\title{
Troubling ideas for widening participation: how higher education institutions in England engage with research in their access agreements.1
}

\author{
Alex Wardrop, Bournemouth University \\ Email: awardrop@bournemouth.ac.uk \\ Maggie Hutchings, Bournemouth University \\ Bethan Collins, University of Liverpool \\ Sue Eccles, Bournemouth University \\ Vanessa Heaslip, Bournemouth University \\ Clive Hunt, Bournemouth University \\ Colin Pritchard, Bournemouth University
}

\section{DOI: http://dx.doi.org/10.5456/WPLL.18.2.xx}

\begin{abstract}
This article explores how higher education institutions in England engage with research in their access agreements. Through an analysis of access agreements from 2014-15 to 2016-17, a picture of how research is understood, undertaken and documented emerges. A lexical analysis of the texts was used to establish the different ways research is being referred to or funded as part of the access agreement process. The analysis shows a productive relationship between national policy and institutional activity. But there appears to be a lack of infrastructure at an institutional and sector level to join up sustained and rigorous research with widening participation activity and policy. This means that, even after ten years of access agreements, widening participation is not fully embedded into the academic practice of higher education. We argue that research undertaken as part of the access agreement process can provide much needed evidence of impact and situate activity within an institution-wide context. However, we also suggest that widening participation research has the potential to offer productive troubling ideas to dominant rhetoric and, in so doing, shape new ways of thinking about, and doing, widening participation within institutions and across the sector.
\end{abstract}

Keywords

Widening Participation, Research, Access Agreements, Institutional transformation 


\section{Introduction:}

Since the introduction of variable fees and the approval of the first access agreements in 2005, these documents have been a statutory requirement for higher education institutions (HEIs) in England wishing to charge above the basic fee (this currently stands at $£ 6,000$ per annum). Institutions are required to outline publically how they will use their higher fee income to support disadvantaged and underrepresented students to enter and progress through higher education [HE]. The access agreements are published by the Office for Fair Access, the independent regulator of access to higher education in England. OFFA defines what must be included in an access agreement as follows:

- $\quad$ proposed tuition fee limits

- the access and student success measures intended to put in place

- how much these measures will cost

- performance targets and milestones

- how institutions will tell students about the financial support offers. ${ }^{2}$

OFFA's most recent strategic guidance for completing the agreements makes it clear that, where possible, institutions should be "building a community of academics and researchers to enhance [their] understanding of effective practice and impact through collaborative research, monitoring and evaluation" (OFFA, 2016b: 5). This means that institutions now have clear statutory guidance to both fund and use research as part of their access agreements. The guidance presents a provocative case for the sector, whereby research could become a key strategy of embedding, and sustaining, widening participation [WP] across an institution.

Access agreements are texts subject to statutory and public scrutiny. Their content lies within a controlled discourse framed by legal requirement and sector and market competition. While they show how HEIs attempt to position themselves within that market and the evidence they use forms part of that performance, the texts can also provide a wealth of information about how institutions fund, draw on, understand and undertake research as part of the development and evaluation of WP activity. This paper is concerned with how universities and colleges in England engage with WP research in their access agreements and how this research could be mobilised to transform institutional practices. This analysis contributes to the growing body of work addressing WP research and evaluation, and supports more productive dialogue between WP policy, practice and research.

This paper is shaped by an analysis of the content of access agreements covering academic years 2014-15 - 2016-17. The data used is drawn from lexical search of terms chosen by the research team and conducted by OFFA. We refined and analysed this data thematically to see how institutions have engaged with WP research activity. We argue that research appears to be troubling for access agreements. This means that while research has become increasingly central to WP policy, it does not sit comfortably within access agreements. We suggest that research could trouble (disrupt, agitate) the dominant market-led discourse of those texts and offer new ways of framing WP for institutions and the HE sector more broadly, particularly concerning collaborative ways of working. 
In the decade since access agreements have been instituted by universities and colleges in England we have seen a 61 per cent increase in students from the areas with the lowest participation rates in higher education (UCAS, 2014). However, evidence from the most recent UCAS data shows that admission rates for the least advantaged group of students in 2015 rose by only 0.3 per cent, compared with 2014 (UCAS, 2015). Further, Dorling (2016) points out that this rise must be compared with the 1.1 per cent increase for the most advantaged group of applicants, thus rather than proportionally increasing opportunities for disadvantaged students, opportunities appear to be decreasing.

This troubling data emphasises the need to reflect on and potentially transform the role of WP within institutions, including the possible leverage afforded through institutional policy and auditing documents, such as access agreements. One of the central tenets of this paper is that for WP to be truly effective it must become more embedded into academic and professional service practice and that one way of doing this is to find ways to incorporate academic research into institutionalised documents like access agreements.

As the primary regulatory vehicle for access to higher education in England, access agreements are useful to think across some of the tensions between a WP discourse which seeks socially aware institutional and sector change, and competitive, market-led institutional rhetoric. They are part of the process of institutional identity formation and performance within a highly stratified HE system. But as documents of, and for, widening participation they also represent a promise, through the reporting of interventions and self-designed targets, of how an institution can change. An analysis of access agreements thus presents the opportunity to think through tensions at the heart of WP discourse and practice; namely, its potential and its performance.

Bowl and Hughes $(2013 ; 2016)$ have argued that the highly controlled nature of the documents means that they present an ambivalent commitment to WP. Institutions maintain, Bowl and Hughes argue, an uneasy "balance between the social justice mission and operating in a global market", suggesting that what can be read presents a move "against social justice" (2013: 23). McCaig (2015) has reinforced these concerns, stressing how institutions use their access agreements to position themselves within a market that is less about education equity than it is competition for student numbers. Rainford (2016) has argued that through their access agreements institutions are interpreting disadvantage for their own purposes and risk targeting support at groups who may not be those most in need. From these perspectives it would seem that access agreements cannot offer the potential for institutional, sector and social change which they might promise.

However, in this paper we want to work with the tensions inherent in access agreements. Troubling tensions are not extraneous to the practice of WP but appear to be at the heart of what challenging and changing higher education might look like. Access agreements exist because there are persistent inequalities within and between institutions and are also being used for marketing purposes. They are troubling documents.

By focusing on the area of research, a way of reading access agreements emerges which makes room both for their hegemonic discourse and, potentially, for its disruption. We argue that research is troubling for access agreements. This means that while research is becoming central to WP policy it does not sit easily 
within access agreements. It is for this reason that research is trouble for access agreements. Being troubling, however, also means that research has the potential to agitate existing discourse and mobilise multiple and contradictory meanings in different ways. ${ }^{3}$ Our focus on how research is being engaged with seeks to demonstrate one way in which access agreements could be used to make tensions between marketisation and transformation more visible and to make positive social change more realisable in the future.

\section{Widening participation and research:}

\section{Conflicting agendas:}

Research in the area of WP is a diverse body of knowledge and knowledge-practices concerned with understanding differences and inequalities in HE participation (including but not limited to, admissions, experiences, attainment, and graduate outcomes). Research is often undertaken with the intention to transform behaviour within a subject, at an institution or across the sector. As such, WP research crosses disciplinary boundaries and those of academic and professional practice. Further, WP research can embrace or often elide with evaluations of particular interventions. Indeed, writing a decade ago, Gorard and Smith (2006) found the whole field of WP research to be intervention-focused evaluations and measured largely through qualitative activity that had little methodological rigour. This means that research in this area has different, at times, conflicting agendas not only in terms of who is doing the research and how and where, but why that research is being undertaken in the first place.

Sheeran et al., (2007) emphasise how WP research is caught between meritocratic, democratic, economic and transformative philosophies - each competing for research impact and policy influence, and supporting different institutional contexts and missions. This pattern of conflicting agendas is read by Jones and Thomas (2005) in terms of WP being a discourse caught between academic, utilitarian and transformative approaches. These dominant approaches - focusing on attainment, aspiration and systemic changes - have contradictory aims and claims. This culture of conflicting agendas in WP research has been seen to contribute to "inconsistencies in institutional practice, with WP operating around contradictory claims, leading to disjointed WP activity" (Stevenson et al., 2010: p107).

Kettley's comprehensive review of WP research argued that any future required "the re-conceptualisation of the field and holistic research agendas" (2007: 343). Rather than being mired in conflict, WP research should work with all of its differences to build productive, sector-wide, knowledge practices. To a certain extent the national strategy, OFFA's evidence strategy and the most recent access agreement guidance could be seen as attempts to realise that future by coordinating and facilitating national research and encouraging greater collaboration within and between institutions (BIS, 2014; OFFA, 2015c; 2016a; 2016b).

However, Kettley's vision for WP research goes further than the coordination of research activity. For it to be effective in changing behaviour, WP research must work with an understanding of the social, economic and material processes and experiences which shape HE and must explore "how the 
differential distribution of resources and skills influences learning" (2007: p343). This is a vision for WP research that embraces reflexivity regarding how education structures can reproduce inequalities. Burke (2012) unpacks this further by highlighting how the hegemonic language of WP policy and research ("social mobility", "aspiration", "transparency", "barriers" etc.,) can reproduce existing inequalities rather than reduce them. The terms we use are shaped within a culture which still privileges certain identities over others. ${ }^{4}$ The research - what or who is researched and how it is talked about - can serve to perpetuate the systems it is seeking to transform.

Positioning research for practice:

Effective WP research, Thompson has argued, must include "investigations that either illuminate or reconcile" the significant paradoxes that appear to be at the heart of WP (2008: 144). Research in this field thus has the potential to be a mirror for institutions and the sector to reflect on what remains unchanged in spite of policy and resource investment. However, Thompson (2008) also argued that research appears incidental to practice and one way to mitigate this is to ensure "that the subject is considered worthy of academic debate in its own right" and that the research has academic standing and is rewarded as such (2008: 144).

Central to Thompson's view is that WP needs to part of an extensive "dialogue concerning the raison d'être of universities in the twenty-first century, and universities' contribution to society, and also drawn into wider research into HE" (2008: p145). This would be supported by Government funding and championing, and "by a more convincing ideological commitment by some institutions than has previously materialised" (2008: p145). The hope for sustained Government funding in this area seems to be a distant one, but Thompson's sentiment presents something far more realisable. WP research - and particularly that funded through and referred to in access agreements - could become part of the practice of HE precisely because it is already invested in this dialogue between students, society, universities and Government.

However, the relationship between institutions and Government is not a simple one. The complexity and contradictions in the research context are mirrored in "the contrasting governmental discourses [which] have not only led to different policy imperatives but to different 'paradigmatic models' of how WP is organised within HEIs" (Stevenson et al., 2010: p107). Stevenson et al. (2010) argue that the complex and contradictory research and policy context has resulted in a climate whereby any sustained, effective, practice is worryingly limited. This reiterates the concerns elaborated by Sheeran et al. (2007), regarding how these competing research positions have created a discursive and practice culture congested with contradictions and risks foreclosing any "real progress" (Sheeran et al., 2007: 259).

Jary and Thomas (1999) called for a community of reflexive-practitioners who could share knowledge, inform practice and assist each other. In this way, research could enable greater collective effort reflecting on, challenging, and finding alternatives to entrenched educative, economic and emotional systems which shape WP.

Seeking transformation by acknowledging uncertainty: 
Widening participation, to repeat Quinn et al., (2005) can "mainstream transformation" in HE and contribute to a vital change in understanding of what university education means. It acts as a reminder that HE is not (yet) for everyone. In doing so, it offers a way of understanding HE which troubles the idea of the university. This means the outcomes of WP research could (and should?) trouble institutions. To include research in public documents which position an institution as already inclusive, diverse, accessible, is to potentially disrupt that performance.

Jones and Thomas (2005) have suggested that the transformative facet of WP has been the area with which institutions and Government have had the most difficulty grappling. They argued that "an access regulator offers the possibility for a transformative higher education in which all institutions, irrespective of status, are required to change ... their policies and practices to facilitate access and success" (2005: p626). However, they emphasise how the dominant discourse of WP - a focus on (perceived) academic ability and economic expediency - all but precludes any transformative approach or understanding within national and institutional policy (Jones and Thomas, 2005).

Archer (2007) has argued that policies which, at first glance, seem to support a move to greater equality and diversity within the sector are being mobilised for a neo-liberal, highly moralised, discourse that aims at silencing the potential of WP. Ahmed argues in On Being Included that diversity has become incorporated or, perhaps institutionalised, in HE. Ahmed writes that "diversity's inclusivity might be here because it is not associated with the inclusion of minorities ... the sign of inclusion makes the signs of exclusion disappear" (Ahmed, 2012: 65). The problem of institutional inequalities becomes normalised and so the problem is not a problem of the institution but for those who expose it and those who are posed as the problem (Ahmed, 2014).

Griffiths (1998) has argued that for education research to work for social justice it must work with "uncertain ways of knowing". Acknowledging the precariousness of a position shaped by "knowledge from different perspectives, in the context of the social and historical situations in which it was discovered, interpreted and constructed" is to self-consciously situate that knowledge as "subject to revision" (Griffiths, 1998: p82). Critically for Griffiths, such knowledge "bears the mark of its knowers" and so "attention must be paid to how it is grounded in the individual perspectives and positions of the researchers and the subjects" (1998: 82). Research, from this perspective, becomes a practice of working with uncertain knowledges developed with others, rather than instituting a hegemonic position.

The uncertain way of knowing that could be understood to shape research for WP creates problems for how it could inform policy and practice. Hammersley (2002), somewhat contentiously, has argued that there is a 'crisis' in the relationship between research and policy precisely because of the uncertainties that shape research. Research-based knowledge is an ongoing dialogue between different evidence, approaches and perspectives. This presents a risk for policymakers who need to be seen to not be "subject to revision". Another dilemma for WP research is the combination of time required to conduct rigorous research and the need for policymakers to have agile responses for a sector in flux. 
When it comes to thinking about research for WP it is important to remember that within English HE, through the regulatory process of the Research Excellence Framework (REF), research as such re-institutes hegemonies because of the way in which funding is distributed, league tables measured and educational quality presumed. Abbas et al., (2013) have emphasised how a system of league tables that is predicated on research quality (re)produces unjust hierarchies that are more to do with the status and wealth of institutions. WP does not exist in a vacuum. It is trying to work in a system entrenched by hierarchical distributions of resource. The research resources available to build reflexive communities and support understandings of effective practice are not evenly distributed across the sector. Those institutions with the most research capacity are not always those doing the most to realise widening participation. Thus, the rewards which Thompson (2008) saw as key to legitimising WP research as a field of knowledge in its own right, are not easily accessible to those undertaking research activity.

\section{Research as community building:}

Reed et al., (2015), in tackling some of the issues relating to WP and policy influence within the Australian context, emphasise how policy influence can be less down to the "clarity of the evidence, and more on matters of timing ... and ... the cognitive or affective dispositions of policy-makers" (2015: 388). The authors advocate a rearticulation of WP to more closely align with "the strategic interests of lobby and advocacy groups, charities, private and public industries or political campaigns" (2015: p391). They suggest such alliances are fiscally sound in a sector increasingly deplete of public resource. Moreover, this approach ensures that the practice (and any evidence drawn from it) is already shaped by the needs of those who live, use and work with it.

Part of the strategy outlined by Reed et al., (2015) is to build and maintain those relationships by engaging in collaborative, ongoing, evaluation activity where any learning from particular interventions can be responded to at a faster pace. Such an understanding of WP evaluation could be beneficial for wider research practices. A sustained and collaborative approach could transform how institutions relate to the Government, student interest groups and the needs of different communities in an English context. This could create a longitudinal body of knowledge and build engaged and participatory relationships between universities and the groups WP policy is intended to support.

Further to using access agreement investment to enhance community engagement, locally, regionally and nationally, we suggest that the documents themselves have the potential to build research relationships across the sector. While we recognise that the documents are discourses thick with market performance, the annual cycle of access agreement development and monitoring does mean that evidence about research activity could be drawn upon by policymakers at institutional and national levels. Access agreements are documents that have the potential to share snapshots of research with a broad audience of interested parties. Conceiving of access agreements in this way, as an ongoing dialogue ("an uncertain way of knowing") between institutions, students and the Government could re-articulate how they are framed and how they are used.

\section{Access agreements and research:}


The national strategy for access and student success makes it clear that research must be used more effectively to support "continuous development and improvement" across the sector (BIS, 2014: p7). This is made even clearer in OFFA's Strategic Plan where increasing understanding of the field is given priority (OFFA, 2015b). These policy initiatives form a turn within WP that seeks to provide a more rigorous understanding of what works in the field (Bowes, 2015; HEFCE, 2010; Nursaw, 2015; Thomas, 2012). The Director of Fair Access, Professor Les Ebdon, spoke in July 2015 of the need for highly selective institutions to harness their research capacity to deliver effective practice. ${ }^{5}$ The most recent guidance from OFFA (2016a; 2016b) builds on this to highlight the importance of harnessing all the expertise available within universities for WP. There appears to be a concerted effort on the part of policymakers to support institutions to fund, undertake and utilise a broad range of research expertise as part of the access agreement process.

However, there is still a long way to go to improve how WP research is undertaken in the context of institutional policy, such as access agreements. Bowes (2015) found great variety in the quality, quantity and dissemination of evidence drawn from national and localised WP evaluation activity. Given the increased investment in access agreements and the significant funding and policy uncertainties that the sector is going through, building sustainable knowledge about what interventions appear to convey the most positive impact in different contexts and developing ways to share that understanding productively must be seen as a priority.

Although there has been a number of studies concerned with the contents and contexts of access agreements (Bowl and Hughes, 2013; 2016; McCaig and Adnett, 2009; McCaig, 2015; Rainford, 2016) and syntheses of WP research (Gorard and Smith, 2006; Kettley, 2007; Sheeran et al., 2007), there has been no study that focuses specifically on how research is engaged in access agreements. In exploring the different ways that research is understood and discussed, this paper calls for greater cohesion between policy, practice and research at institutional levels to inform and influence national and international policy.

We argue that in addition to being used to inform practice and evaluate impact, research has the potential to trouble the hegemonic discourse of access agreements that sees a commitment to social justice being marginalised by a commitment to market position. ${ }^{6}$ In so doing, research could offer a way back to an understanding of WP as expressed by Thompson as:

"...about developing a sustained critique of current rhetoric, developing a distinctive social theory of knowledge derived from a politically committed analysis and theory of power ... [leading] to a form of pedagogy that is concerned to democratise knowledge making and learning..."(Thompson, 2000: 10).

\section{Method:}

Access agreements are publically available documents that can be accessed online for free in PDF format. ${ }^{7}$ We wanted to find out how WP research - broadly speaking - was being engaged with by both universities and colleges. With this in mind, we wanted to look at the whole body of access agreements over more than one academic year. To make the research manageable we asked OFFA to share with us data pulled from a lexical search of all access agreements 
from academic years from 2014-15 to 2016-17. The search was conducted using the qualitative data software package, MaxQDA. This software allows large datasets of different text items to be structured and analysed in one place. It means that a large of body of texts, like access agreements, can be researched as a group to enable broad themes and trends to be examined over time. We opted for a lexical search because it allows us to capture how institutions themselves conceive of WP research activity within their access agreements. We acknowledge that this approach can reduce the complex and not readily apparent motives and meanings behind the texts; however, we wanted a broad look at how the whole sector was engaging with research activity.

We drew together a list of key words which could capture how WP research activity, and in particular, academic research, is being documented:

\begin{tabular}{|l|}
\hline Academic \\
\hline Action Research \\
\hline Analysis \\
\hline Co-production \\
\hline Doctoral \\
\hline Evidence/Evidence-base/Evidenced \\
\hline Lecturer \\
\hline PhD/Doctoral \\
\hline Post-doctoral/Postdoctoral \\
\hline Practice-led/Practice led \\
\hline Research/Research-informed/Researcher/Researchers \\
\hline Qualitative \\
\hline Quantitative \\
\hline
\end{tabular}

The raw text data was refined to remove errors and duplicates. This included removing references to research being undertaken by institutions that was not part of WP activity. This refined data was assessed in terms of how the references to research related to institutions' discussions of their broader evaluation practices. The text data was then analysed thematically along the terms of different types of research activity (for example, evaluative, academic-focused, collaborative etc.). This allowed us to see how more in depth research activity is being undertaken (for example, mixed-methods approaches). We realised from the initial analysis that institutions were engaging in research activity that included evaluations of specific interventions. Where institutions situated their evaluations within deeper research frameworks, we included this as research activity.

Extracts from four institutions were examined to compare how research is figured in different institutional contexts. Our small sample was chosen to include a mixture of institution type (FE college, pre-1992, post-1992) in a variety of different geographic settings and with different capacities for undertaking WP 
research. These examples do not claim to be representative of the whole sector but provide a glimpse into the different ways different HEIs engage with research.

The methodology used means that the understanding of research underpinning this paper rests on how institutions themselves conceive of and presented their WP practices (i.e. if institutions defined their practices in terms of the language of research, evidence and analysis). We wanted a broad overview of how research activity is being presented by institutions in access agreements rather than to unpick the complex discourses of power that are at play in those presentations. A productive study that could develop from this data could establish in more detail why different institutions construct their approaches to research in different ways.

All institutions with an access agreement must undergo annual monitoring of their performance through the submission of access agreement monitoring returns (OFFA and HEFCE, 2015). The data here refers to activity that is being engaged in addition to the minimum statutory monitoring requirements.

\section{Findings:}

The major finding is that there has been a consistent increase in institutions referring to WP research, evaluation and analysis activity from academic years 2014-15 - 2016-17:

\begin{tabular}{|l|c|c|c|}
\hline Academic Year & $2014-15$ & $2015-16$ & $2016-17$ \\
\hline Institutions with access agreements $^{8}$ & 162 & 172 & 183 \\
\hline WP research, evaluation, analysis & 109 & 123 & 151 \\
\hline Percentage & $67 \%$ & $72 \%$ & $83 \%$ \\
\hline
\end{tabular}

This growth in WP research, evaluation and analysis should be seen within a broader policy context of increased calls to improve the evidence and understanding (for example, OFFA's access agreement guidance and the national strategy). This period also saw the expansion of evaluation and tracking activity across the sector (most notably, the Higher Education Access Tracker (HEAT). These policy and auditing developments have created the infrastructure and drivers to acknowledge the need for increasing research to influence, promote and support increased and effective activity.

Nature of research:

We examined this broad data in more detail to tease out how more indepth research activity was being engaged with. We looked at references to established research methodologies (including action research), mixed method studies, longitudinal approaches, and where institutions stated they were engaging in robust research studies:

\begin{tabular}{|l|c|c|c|}
\hline Year & $2014-15$ & $2015-16$ & $2016-17$ \\
\hline Institutions with access agreements & 162 & 172 & 182 \\
\hline In-depth WP research & 53 & 52 & 95 \\
\hline Percentage & $35 \%$ & $30 \%$ & $52 \%$ \\
\hline
\end{tabular}


There is a 22 percentage point increase in references to more in depth research activity from 2015-16 to 2016-17. The guidance for the 2016-17 access agreement process was published in January 2015 and it included greater emphasis on institutions demonstrating "smarter evidence-based spend" (OFFA, 2015a: 4). Institutions would also have had the policy insight, case studies and research reviews of the national strategy to inform their completion of the 201617 access agreements. Indeed, the national strategy emphasises the need for institutions to undertake robust evaluations and draws attention to the Evaluation Toolkits designed by Dent et al., (2013).

The data shows an increase in more in depth research activity and is suggestive of a sector responsive to national policy guidance. However, although there are improvements in this area, we only see half of all institutions outlining more detailed WP research. This is in spite of calls since 2010 to conceive of WP evaluation and research in such a way (HEFCE, 2010). This suggests a persistent hesitancy to include deeper, more rigorous, understandings of research in access agreement processes, including for evaluation purposes.

\section{Academic involvement:}

When one looks at references to academic involvement in WP research we see increasing engagement. However, only a quarter of institutions state they involve academics in their WP research activity:

\begin{tabular}{|l|c|c|c|}
\hline Academic Year & $2014-15$ & $2015-16$ & $2016-17$ \\
\hline Institutions with access agreements & 162 & 172 & 183 \\
\hline $\begin{array}{l}\text { Academic involvement in WP } \\
\text { research }\end{array}$ & 22 & 35 & 44 \\
\hline Percentage & $14 \%$ & $20 \%$ & $24 \%$ \\
\hline
\end{tabular}

When it comes to access agreements at least, academic involvement in WP research appears limited. One reason for this is to do with how WP structurally sits within many institutions. Stevenson et al., (2010) elaborate how much work in this area, particularly work involving academics, is contoured by informal, highly individualised, networks with little consistent institutional "scaffolding" (2010: 112). This can make it difficult for academic research to be drawn on in access agreement development. ${ }^{9}$

\section{Research infrastructure:}

Our analysis shows that there are only a limited number of dedicated research centres, institutes or groups within institutions that could act as catalysts for knowledge-exchange between practitioners and academics. In the 2016-17 access agreements, only 32 institutions make reference to having a dedicated WP research spaces.

However, the access agreements present a picture of research activity that goes beyond academic research being conducted in specialist centres. When the data from the key terms was analysed it became clear that a broad range of WP research infrastructure was to be found. In framing our understanding of the WP research infrastructure we took into account institutions reporting dedicated members of staff for WP research, enhancing data systems and tracking activity, 
engaging in collaborative research networks and activity, and demonstrating strategies for undertaking, responding to, and disseminating research:

\begin{tabular}{|l|c|c|c|}
\hline Academic Year & $2014-15$ & $2015-16$ & $2016-17$ \\
\hline $\begin{array}{l}\text { Total number of institutions with access } \\
\text { agreements }\end{array}$ & 162 & 172 & 182 \\
\hline WP research infrastructure & 63 & 79 & 102 \\
\hline Percentage & $39 \%$ & $46 \%$ & $56 \%$ \\
\hline
\end{tabular}

\section{Characteristics of research:}

Within the texts, institutions make reference to local, national and international research as they provide rationale for their activities (and their expenditure). However, it should be noted that references to international research activity is limited, with only four institutions doing so. This seems a curious absence, given the wealth of knowledge that could be drawn on to shape practice and the established international research infrastructure that a number of English higher education institutions are actively involved with (the European Access Network, the European Union's Eurydice programme and Global Access to Postsecondary education). ${ }^{10}$

The majority of the research referred to focuses on the evaluation of the impact of localised projects - whether they are outreach, financial support measures or those aimed at improving retention. That the activity detailed in access agreements is funded through income accrued through students' tuition fees means that finding ways to evaluate expenditure and measure how it best supports students is central.

From surveying how research is being discussed we can see three main characteristics:

- Defensive (justifying spend)

- Reactive (responding to crisis)

- Productive (changing behaviour)

Perhaps unsurprisingly it seems that the most important role that research has is to defend behaviour and justify expenditure. An illustration of research characterised as defensive is that directed at financial support. In this academic year (2015-16), over half of the institutions engaging in research activity make some reference to research in relation to financial support. This includes reference to research being undertaken at a particular institution and to institutions stating they are being informed by, or aware of, national evidence. As Nursaw (2015) attests, however, research in the area of financial support is not as robust as it could be, suggesting that research is not being used as effectively as it could to "generate useful knowledge and to inform and assist others" (Jary and Thomas, 1999: 7). Rather, it is being used to justify an existing standpoint.

This defensive aspect to how research is being discussed leads to how research is being mobilised in a reactive capacity. An example of this is reference to research focusing on the attainment and outcomes of Black and Minority Ethnic (BME) students. In the 2015-16 access agreements twenty-one institutions document some form of research, analysis, and/or evaluation activities that specifically focuses on the participation, experiences and progression of BME 
students. ${ }^{11}$ However, this research does not for the most part outline any proposed changes in behaviour or reflect on how the structures of HE work to enforce gaps in belonging and can re-produce colonial hierarchies (Coleman, 2015). The recent student-led campaigns and protests in England and across the globe calling for a decolonisation of the university (whether that is the buildings, the curricula, the staff, the students, or the cocktails) are a palpable illustration of how HE is not self-consciously addressing its painful legacies of knowledge, power and privilege. ${ }^{12}$ Such forms of reactive research could suggest that these institutions are not drawing on their capacity for self-reflection or on the expertise within their institution to decolonise academic practice, including in the area of WP. In this instance, research is being mobilised to react to the status quo rather than actively change it.

This brings us to the final, and least referred to, characteristic of research elucidated in the access agreements, the productive. Institutions can be characterised as using research productively when they cite research activity or outcomes as part of a change in behaviour to enhance student participation and/or experience. An example of such productive research can be seen in pedagogical or pastoral changes to enhance student involvement as a result of research undertaken. In 2015-16, only 11 institutions make reference to how research has led to changes in pastoral or pedagogic practice. There are number of reasons that could account for the limited frequency of references to research changing behaviour. These might include the long lead-in time of some research (the outcomes are not yet here), tensions between research and practice outlined above (it is not always easy to quantify if, and how, research has changed practice), and institutional structures that may not see teaching and learning as part of the access agreement process.

\section{Examples from institutions:}

In spite of the difficulties in mobilising research for WP, we can see institutions approaching the issue in a variety of different ways. We will now, very briefly, look at how different institutions do so. The institutions are anonymised and are drawn from different geographic, research and student contexts: 


\begin{tabular}{|c|c|c|}
\hline Institution & Type & Research Activity \\
\hline $\mathrm{A}$ & $\begin{array}{l}\text { A highly selective university in the } \\
\text { north of England. The institution has } \\
\text { a school of education and academics } \\
\text { working in the area of WP. The } \\
\text { institution was in the top five } \\
\text { universities who submitted for the } \\
\text { REF Unit of Assessment } 25 \\
\text { (education). }\end{array}$ & $\begin{array}{l}\text { The University is employing the } \\
\text { services of its Centre ... which is } \\
\text { the largest independent provider } \\
\text { of educational monitoring systems } \\
\text { in the world and provides } \\
\text { specialist research and evaluation } \\
\text { services to a wide range of } \\
\text { organisations } \\
\text { universities ... The University is } \\
\text { also collaborating in a research } \\
\text { project to } \\
\text { evaluate the retention benefits of } \\
\text { bursaries. (2016-17 access } \\
\text { agreement). }\end{array}$ \\
\hline $\mathrm{B}$ & $\begin{array}{l}\text { Further education college with higher } \\
\text { education provision in the rural south } \\
\text { of England. The institution has a } \\
\text { foundation degree programme in } \\
\text { education practice. }\end{array}$ & $\begin{array}{l}\text { Research undertaken in 2012-13 } \\
\text { highlighted that a lack of } \\
\text { awareness of job opportunities for } \\
\text { graduates was a barrier to } \\
\text { entering higher education ... } \\
\text { Focus groups undertaken with } \\
\text { internally progressing students } \\
\text { reflected these concerns. In } \\
\text { response, WP activity aims to } \\
\text { increase understanding of of } \\
\text { progression ... (2016-17 access } \\
\text { agreement). }\end{array}$ \\
\hline $\mathrm{C}$ & $\begin{array}{l}\text { Post-1992 university in suburban } \\
\text { London, with teaching and research } \\
\text { programmes focusing on education. }\end{array}$ & $\begin{array}{l}\text { The Student Academic } \\
\text { Development and Research } \\
\text { Associate Scheme (SADRAS) is } \\
\text { jointly co-ordination [sic] by the } \\
\text { University's Centre ... and the } \\
\text { Students Union. It provides } \\
\text { students with the opportunity to } \\
\text { work alongside academic staff in } \\
\text { undertaking educational and } \\
\text { pedagogic research. The scheme } \\
\text { assists students in gaining } \\
\text { experience of professional } \\
\text { practice in the academic sector } \\
\text { and facilitates academic staff } \\
\text { involvement in pedagogic research } \\
\text { in relation to the WP agenda } \\
\text { (2016-17 access agreement). }\end{array}$ \\
\hline
\end{tabular}




\begin{tabular}{|l|l|l|}
\hline $\mathrm{D}$ & $\begin{array}{l}\text { Post-1992 university in a coastal area } \\
\text { with no education research } \\
\text { department/faculty but with a centre } \\
\text { for teaching and learning. }\end{array}$ & $\begin{array}{l}\text { [University] is committed to } \\
\text { developing a strong evidence base } \\
\text { to inform decisions on service } \\
\text { provision and resource allocation } \\
\text {...we have embarked on a } \\
\text { longitudinal study [and] to } \\
\text { undertake action research to } \\
\text { narrow any gaps that we find... } \\
\text { the findings of this research will } \\
\text { not only inform practice ... but } \\
\text { will be widely disseminated, with } \\
\text { the ambition of also developing } \\
\text { national collaborations for future } \\
\text { practice (2016-17 access } \\
\text { agreement). }\end{array}$ \\
\hline
\end{tabular}

Institution B is the smallest of our sample and does not have an extensive WP department or an education research focus. The research detailed here is of the qualitative, intervention-based, type which Gorard and Smith (2006) critiqued a decade ago. However, in this text, research is understood in terms of how it has enabled a change in practice and an increased understanding of the student journey. This suggests that level of resource is not the only factor in determining whether or not institutions are funding, undertaking or drawing on research activity as part of their access agreement process.

Institution $\mathrm{C}$ demonstrates a sophisticated research infrastructure with both academics and students participating the in research process. A named research scheme is being implemented with the dual purpose of increasing understanding of the field and building students' capabilities.

The approach to research outlined in Institution D appears future-oriented, outlining the development of longitudinal research activity. This suggests an institution growing a sustainable research infrastructure rather than using research just for the development or evaluation of specific projects.

Institution C frames research activity as part of a wider WP 'agenda', while Institution D makes it clear that its development of sustainable WP research forms part of how it seeks to influence the sector. For these two institutions, we can see WP research becoming part of the brand of these universities as they negotiate their positions in an increasingly competitive field (McCaig, 2015).

Institution A has the most robust academic research infrastructure, with internationally ranked expertise in the field of education. However, references to research in the text are limited to a focus on evaluation and monitoring. It makes no reference to the extensive WP research being undertaken by academics at that institution. One reason for this lies in understanding and appreciating the scope of access agreements, particularly for highly selective institutions (Rainford, 2016). With this in mind, research which points to the problem of participation could become a problem for such documents.

However, all our extracts do highlight a crucial characteristic of how WP research is becoming imagined by the sector (as reflected in the most recent OFFA guidance); as a collective effort to build and share knowledge, between institutions, students, Students' Unions and other stakeholders. 
Our purpose here has been to illuminate the different ways institutions describe their engagement with research activity in their access agreements. These examples illustrate some of the thinking at the heart of this paper, namely that research doesn't sit easily within access agreements, becomes part of institutional market presentation and is being used to build communities within institutions and across the sector.

\section{Discussion and Conclusions:}

The findings outlined here suggest that although institutions are building their capabilities in the area of WP research, the primary role of research in access agreements appears to be mobilised to defend or justify expenditure.

However, given that there remains a long way to go before HE in England can claim to be fair, equitable and enabling wider social justice, developing, undertaking and disseminating more systematic and socially aware research which examines why there remain significant differences in participation and outcomes must be a priority for the sector. From what is being reported in access agreements, at least, the future of widening participation research that Kettley (2007) envisaged has not yet arrived. Perhaps the clear guidance from OFFA for the 2017-18 access agreements about sustainable, collaborative research could help bring that horizon a little nearer to us.

This analysis appears to confirm the WP culture that Stevenson et al., (2010) outlined whereby "the responsibility for supporting WP students once in higher education was variously regarded, with some staff feeling that that it was either not their responsibility or that they could leave students 'to it' once they were on their courses" (2010: 113). Because WP, as such, remains not fully or sustainably embedded in the mainstream practice of HE (although this varies across the sector), research for WP remains a troublesome facet of that discourse. This means that although we can see a collective effort to invest resource in this area and build understanding, research risks being used in access agreements to maintain a status quo rather than change practice.

That the Government's White Paper proposes incorporating the singlefocused regulator for fair access within a larger HE regulatory body (the proposed Office for Students) is a concern for WP research (BIS, 2015; BIS, 2016). This is because our findings suggest a sector that is, slowly, responding to guidance and working with policymakers and each other to build capacity and communities for research. What is a worry is that without a single-focused regulator of fair access that productive relationship could be put at risk.

Ensuring that there remains a focused Government infrastructure to support institutions to draw on their knowledge-base and expertise in this area is one of the major recommendations of this paper. Finding ways to support institutions to build internal links, enhance reflexive practice and embed WP into HE practice could be one way for the Government to ensure that the collective effort of WP does not get forgotten. Given the varied resources available at different institutions, making sure that research, in some form, underpins all activity (and, in turn, that that activity shapes and informs research) is important. This will require a courageous and collective effort of learning and sharing expertise, in the face of a highly competitive and stratified sector, both in terms of 
research and student numbers. This in itself could be a troubling idea for researchers and practitioners in the field.

This paper set out to elaborate how HEIs in England engage with WP research their access agreements. We found that within the highly controlled and negotiated discourses of access agreements, research occupies a troubling position. There remains a persistent hesitancy to include academic-focused research in these texts. If research for WP is to be an "integral part of practical initiatives and to encourage an iterative learning process between practice, research and policy", the disengaged use of research within publicly available policy documents that outline practice presents a very troubling idea for all those invested in and committed to transforming HE in England (Jary and Thomas, 1999: p7).

By seeing research activity as part of a transformative process that should be central to WP we have suggested that access agreements have the potential to be seen as an ongoing dialogue between institutions, students and the Government. In an uncertain time for HE in England, embracing uncertain ways of knowing could enable a more transformative way of (re)engaging with WP in England.

\footnotetext{
${ }^{1}$ We would like to thank Ankaret Fillipich and Dr Becka Wallbridge for providing the raw data for this research. We would also like to thank our reviewers who have helped us enormously in clarifying our thinking and checking our assumptions.

${ }^{2}$ Available at: https://www.offa.org.uk/universities-and-colleges/introducing-access-agreements/

${ }^{3}$ Such an understanding of 'trouble' is drawn from the thinking developed by political theorist Judith Butler in the book Gender Trouble (2006).

${ }^{4}$ For an elaboration of how class-based assumptions and privileges shape (or, perhaps, misshape) participation and experiences at U.K. universities see Reay et al., (2009).

${ }^{5}$ Professor Ebdon was speaking at The Brilliant Club conference at Kings College London. He stated, "OFFA has already begun to work closely with university researchers to improve evidence and understanding, and the whole sector will benefit from sharing the outcomes of this work". (BBC News, 08/07/2015). Available at: http://www.bbc.co.uk/news/education-33430921

${ }^{6}$ Social justice is being understood here as an ongoing process concerned "with questions of power and resources available to individuals and particular communities or sectors of those communities" (Griffiths, 1998: 13).

${ }^{7}$ Access agreements are available at: https://www.offa.org.uk/access-agreements/

${ }^{8}$ This excludes the Open University because the OU operates outside the main access agreement cycle. For an indication of the widening participation research activity being undertaken at the OU see: http://www.open.ac.uk/cicp/main/

${ }^{9}$ Although beyond the scope of this paper, as we are concentrating on universities in England with an access agreement, the Irish model offers a productive example of researcher-engaged practice. Researchers work within WP departments or programmes both in the development and evaluation of particular interventions. See for example, the Trinity Access Programme at Trinity College Dublin: http://www.tcd.ie/Trinity_Access/

${ }^{10}$ For European Access Network see: http://www.ean-edu.org/; for the Eurydice Network see: https://webgate.ec.europa.eu/fpfis/mwikis/eurydice/index.php/Main_Page; for GAPs see: http://www.gapseducation.org/

${ }^{11}$ This is in addition to statutory monitoring activity as part of the Equalities Act 2010 and the Race Relations Act Amendment 2010. For differences in degree outcomes see HEFCE (2010).

${ }^{12}$ The Rhodes Must Fall protests taking place across the globe draw attention to how HE has been shaped by hierarchies and colonialisation and how those legacies still affect students and staff. For more information see: http://rhodesmustfall.co.za/. UCL's Dismantling The Master's House community seeks to unpack the legacies of racialised hierarchies that have shaped, and continue to shape, the very architecture of the institution, including what, and who, is taught or not taught in curricula. Available at: http://www.dtmh.ucl.ac.uk/
} 


\section{References:}

Abbas, A., McLean, M. and Ashwin, P. (2013) 'Qualitative Life-grids: A proposed method for comparative European educational research', European Educational Research Journal, 12, 3: 320-329.

Ahmed, S. (2012) On Being Included: Racism and Diversity in Institutional Life, London: Duke University Press.

Ahmed, S. (2014) 'The Problem of Perception' [Online] Available at: http://feministkilljoys.com/2014/02/17/the-problem-of-perception/ (accessed: 22 October 2015).

Archer, L. (2007) 'Diversity, equality and higher education: a critical reflection on the ab/uses of equity discourse within widening participation', Teaching in Higher Education, 12, 5/6: 635-653.

Bowes, L. (2015) Student Opportunity outcomes framework research: in-depth study: Report to HEFCE by CFE Research, Bristol: HEFCE.

Bowl, M. and Hughes, J. (2013) 'Discourses of "Fair Access" in English Higher Education: what do institutional statements tell us about university stratification and market positioning?', Journal of Widening Participation and Lifelong Learning, 15, 4: 7-25.

Bowl, M. and Hughes, J. (2016) 'Fair access and fee setting in English universities: what do institutional statements suggest about university strategies in a stratified quasi-market?', Studies in Higher Education, 41, 2: 269-287.

Burke, P.J. (2012) The Right to Higher Education: Beyond Widening Participation, Oxford: Routledge.

Butler, J. (2006). Gender trouble: feminism and the subversion of identity, Oxford: Routledge.

Coleman, N.A.T (2015) 'Diversity is a dirty word' at Developing Diversity Competence, 2nd annual Equality Challenge Unit (ECU) and Higher Education Academy (HEA) Scotland conference, Edinburgh [23/04/15]. [Online]. Available at: https://www.academia.edu/12156321/Diversity_is_a_dirty_word_-_UK (accessed 8th December 2015).

Dent, P., Garton, L., Hooley, T., Leonard, C., Marriott, J., and Moore, N. (2014) Higher Education Outreach to Widening Participation: Toolkits for practitioners, EVALUATION, York: Higher Education Academy.

Department for Business, Innovation and Skills (2014) National strategy for access and student success in higher education, by HEFCE and OFFA, London: Cabinet Office.

Department for Business, Innovation and Skills (2015) Fulfilling our potential: teaching excellence, social mobility and student choice, London: Cabinet Office. 
Department for Business, Innovation and Skills (2016) Success as a Knowledge Economy: Teaching Excellence, Social Mobility and Student Choice, London: Cabinet Office.

Dorling, D. (2016) 'Danny Dorling on university admissions and inequality', The Times Higher Education, 4 February, 2016.

Equality Act 2010 (2010), London: Stationary Office.

Gorard, S. and Smith, E. (2006) 'Beyond the "learning society": what have we learnt from widening participation research?', International Journal of Lifelong Learning Education, 25,6: 575-94.

Griffiths, M. (1998) Educational Research for Social Justice: getting off the fence, Buckingham: Open University Press.

Hammersley, M. (2002) Educational Research: Policymaking and Practice, London: SAGE Publications.

Higher Education Funding Council for England (2010) Widening participation strategic assessments: guidance on developing evaluative approaches to widening participation activities and commitments, Circular Letter 24/10, Bristol: HEFCE

Higher Education Funding Council for (2015) Differences in degree outcomes: the effect of subject and student characteristics, Bristol: HEFCE.

Jary, D. and Thomas, L. (1999) 'Widening Participation and Lifelong Learning: Rhetoric or Reality? The Role of Research and the Reflexive Practitioner', Journal of Widening Participation and Lifelong Learning, 1, 1: 1-10.

Jones, R. and Thomas, L. (2005) 'The 2003 UK Government Higher Education White Paper: a critical assessment of its implications for the access and widening participation agenda', Journal of Education Policy, 20, 5: 615-630.

Kettley, N. (2007) 'The Past, Present and Future of Widening Participation Research', British Journal of Sociology of Education, 28, 3: 333.347.

McCaig, C. (2015) 'The impact of the changing English higher education marketplace on widening participation and fair access: evidence from a discourse analysis of access agreement', Journal of Widening Participation and Lifelong Learning, 17, 1: 5-22.

McCaig, C and Adnett, N (2009) 'English Universities, Additional Fee Income and Access Agreements: their impact on Widening Participation and Fair Access', British Journal of Education Studies, 57,1:18-36.

Nursaw, C. (2015) What do we know about the impact of financial support on access and student success, Bristol: OFFA.

Office for Fair Access (2013) How to produce an access agreement for 2014-15 [2013/01], Bristol: OFFA.

Office for Fair Access (2015a) How to produce an access agreement for 2016-17 [2015/01], Bristol: OFFA. 
Office for Fair Access (2015b) Strategic Plan 2015-2020, Bristol: OFFA.

Office for Fair Access (2015c) Evidence Strategy, Bristol: OFFA.

Office for Fair Access (2016a) How to produce an access agreement, a step-by-step guide, Bristol: OFFA.

Office for Fair Access (2016b) Strategic guidance: developing your 2017-18 access agreement, Bristol: OFFA.

Office for Fair Access and Higher Education Funding Council for England (2015) How to complete your 2014-15 monitoring return: Access agreements, Student Opportunity Allocation and the National Scholarship Programme, Bristol: OFFA/HEFCE.

Quinn, J., Thomas, L., Slack, K., Vigurs, K. and Flynn, N. (2005) 'Learners on their own terms? Learning brokerage, mainstream transformation and social exclusion', Journal of Access Policy and Practice, 3,1: 21-44.

Race Relations (Amendment) Act (2010), London: Stationary Office.

Rainford, J. (2016) 'Targeting of widening participation measures by elite institutions: widening access or simply aiding recruitment?', Perspectives: Policy and Practice in Higher Education.

Reay, D., Crozier, G. and Clayton, J. (2009) 'Strangers in Paradise: Working class students in elite universities', Sociology, 43,6: 1103-1121.

Reed, R., King, A. and Whiteford, G. (2015) 'Re-conceptualising sustainable widening participation: evaluation, collaboration and evolution', Higher Education Research and Development, 34, 2: 383-39.

Sheeran, Y., Brown, B.J. and Baker, S. (2007) 'Conflicting philosophies of inclusion: The contestation of knowledge in widening participation', London Review of Education, 5, 3: 249-63.

Stevenson, J., Clegg, S. and Lefever, R. (2010) 'The discourse of widening participation and its critics: an institutional case study', London Review of Education, 8, 2: 105-115.

Thomas, L. (2012) Building student engagement and belonging in higher education at a time of change: final report from the What Works? Student Retention \& Success programme, London, Paul Hamlyn Foundation.

Thompson, D.W. (2008) 'Widening participation and higher education. Students, systems and other paradoxes', London Review of Education 6, 2: 137-47.

Thompson, J. (2000) 'Introduction' in Thompson, J. [ed] Stretching the Academy: The politics and practice of widening participation in Higher Education, Leicester: NIACE.

Thompson, J. [ed] Stretching the Academy: The politics and practice of widening participation in Higher Education, Leicester: NIACE. 
UCAS (2014) UCAS: End of Cycle Report, UCAS: Cheltenham.

UCAS (2015) UCAS: End of Cycle Report, UCAS: Cheltenham. 